\section{A) Check for updates}

Cite this: Analyst, 2017, 142, 3194

\title{
Electrochemical behaviour at a liquid-organogel microinterface array of fucoidan extracted from algae $\uparrow$
}

\author{
Bren Mark B. Felisilda, ${ }^{a}$ Eva Alvarez de Eulate, ${ }^{a}$ Damien N. Stringer, ${ }^{b}$ J. Helen Fitton ${ }^{b}$ \\ and Damien W. M. Arrigan (D) *a
}

Fucoidans are sulfated polysaccharides mostly derived from algae and used in a number of applications (e.g. nutrition, cosmetics, pharmaceuticals and biomaterials). In this study, the electrochemical behaviour of fucoidans extracted from two algal species (Undaria pinnatifida and Fucus vesiculosus) was assessed using voltammetry at an array of micro-interfaces formed between two immiscible electrolyte solutions ( $\mu$ ITIES) in which the organic electrolyte phase was gelled. Cyclic voltammetry revealed an adsorption process when scanning to negative potentials, followed by a desorption peak at ca. $-0.50 \mathrm{~V}$ on the reverse scan, indicating the electroactivity of both fucoidans. U. pinnatifida fucoidan showed a more intense voltammetric signal compared to $F$. vesiculosus fucoidan. In addition, use of tridodecylmethylammonium $\left(\mathrm{TDMA}^{+}\right)$or tetradodecylammonium $\left(\mathrm{TDDA}^{+}\right)$as the organic phase electrolyte cation provided improved detection of both fucoidans relative to the use of bis(triphenylphosphoranylidene)ammonium $\left(\mathrm{BTPPA}^{+}\right)$cation. Application of adsorptive stripping voltammetry provided a linear response of current with fucoidan concentration in the range $2-20 \mu \mathrm{g} \mathrm{mL}^{-1}$ for $U$. pinnatifida fucoidan (with $\mathrm{TDMA}^{+}$) and 10-100 $\mu \mathrm{g} \mathrm{mL}^{-1}$ for $F$. vesiculosus fucoidan (with $\mathrm{TDDA}^{+}$). The combination of $\mathrm{TDMA}^{+}$in the organic phase and adsorptive pre-concentration for $180 \mathrm{~s}$ afforded a detection limit of $1.8 \mu \mathrm{g} \mathrm{mL}{ }^{-1}$ fucoidan (U. pinnatifida) in aqueous phase of $10 \mathrm{mM} \mathrm{NaOH}$ and $2.3 \mu \mathrm{g} \mathrm{mL}^{-1}$ in synthetic urine ( $\mathrm{pH}$ adjusted). These investigations demonstrate the electroactivity of fucoidans at the $\mu$ ITIES array and provide scope for their detection at low $\mu \mathrm{g} \mathrm{mL}^{-1}$ concentrations using this approach.

Received 8th May 2017, Accepted 16th July 2017 DOI: 10.1039/c7an00761b

rsc.li/analyst density and degree of branching. ${ }^{4-6}$ However, despite such differences, they are all negatively charged polyelectrolytes. ${ }^{7}$

The uses of fucoidan are diverse and have been the focus of several studies, ranging from biological and biomedical activities to food and nutraceutical applications. For instance, fucoidan was found to have higher antioxidant capacity and higher dietary fibre content than some commercial non-fucoidan nutraceutical counterparts, ${ }^{8}$ as discussed in a recent review. ${ }^{9}$ Fucoidan was found to induce apoptosis of some human cancer cells (colon, urinary bladder, and lymphoma cancer cells) $)^{10-12}$ and was also investigated for other cancer therapies. ${ }^{13,14}$ Moreover, fucoidan was reported to help minimise osteoarthritis, ${ }^{15}$ to have immunomodulatory effects ${ }^{16}$ and to inhibit retroviruses such as the herpes simplex virus and the human immunovirus (HIV). ${ }^{17-19}$ Given its range of practical applications, a simple and direct detection method for measuring the presence of fucoidan is desirable. In order to establish fucoidan's bioactivity, quantitative measurements are required in blood or urine samples to elucidate its metabolic pathway. ${ }^{9}$ Techniques currently used for fucoidan detection include electrophoresis coupled with infra-red and Raman
${ }^{a}$ Curtin Institute of Functional Molecules and Interfaces, Department of Chemistry, Curtin University, GPO Box U1987, Perth, WA 6845, Australia.

E-mail:d.arrigan@curtin.edu.au

${ }^{b}$ Marinova Pty Ltd., 249 Kennedy Drive, Cambridge, Tasmania 7170, Australia $\dagger$ Electronic supplementary information (ESI) available. See DOI: 10.1039/ c7an00761b 
spectroscopies, ${ }^{20,21}$ fluorimetric assays ${ }^{22,23}$ and enzyme-linked immunosorbent assay (ELISA) using anti-fucoidan antibodies. ${ }^{24,25}$ The ELISA approach detected $c a .4 \mathrm{mg} \mathrm{L}^{-1}$ and $c a$. $13 \mathrm{mg} \mathrm{L}^{-1}$ in plasma from healthy volunteers that had ingested fucoidan preparations containing $10 \%$ and $75 \%$ fucoidan, respectively. ${ }^{24}$ Furthermore, ELISA analysis of serum, plasma and urine samples from healthy volunteers administered with Cladosiphon okamuranus fucoidan indicated that urine fucoidan levels were in the range of $0.1-0.9 \mu \mathrm{g} \mathrm{mL}^{-1}$, while the corresponding serum and plasma levels were in the range of 0.01-0.07 $\mu \mathrm{g} \mathrm{mL} \mathrm{m}^{-1},{ }^{25}$ indicating the range of concentrations that must be detected by a new analytical strategy. Generally, ELISA methods need sample pre-treatment, several washing steps and several hours of incubation. A recent fluorimetric assay reported a detection limit of $0.025 \mathrm{ng} \mu \mathrm{L}^{-1}$, in buffer solution, using SYBR Gold nucleic acid stain as the fluorescent dye, ${ }^{22}$ while another method, using Heparin Red as the fluorescent probe, detected fucoidan in the range of 0.5-20 $\mu \mathrm{g} \mathrm{mL} \mathrm{L}^{-1}$, including in spiked human plasma. ${ }^{23}$

The need for fast, low-cost and sensitive methods has focused attention on electrochemical detection platforms. Potentiometric ion-selective electrodes (ISEs) employing a polymer membrane doped with tridodecylmethylammonium $\left(\mathrm{TDMA}^{+}\right)$have been explored to detect negatively charged macromolecules like carrageenan, ${ }^{26} \mathrm{DNA}^{27}$ heparin $^{28,29}$ and pentosan polysulfate. ${ }^{30}$ Kim et al. ${ }^{31}$ investigated several species of fucoidan using polyion-sensitive ISEs. They found that the species of algae and the extraction method used influenced the charge density and polymer backbone composition of fucoidan, and consequently the ISE response. Detection at concentrations as low as ca. $2.5 \mu \mathrm{g} \mathrm{mL}{ }^{-1}$ fucoidan using titrimetry was reported. ${ }^{31}$

In recent decades, there has been an increased interest in the electrochemistry of the interface between two immiscible electrolyte solutions (ITIES) as the basis for new analytical strategies. ${ }^{32,33}$ Since electrochemistry at the ITIES offers advantages such as label-free detection and amenability to miniaturization, ${ }^{34}$ it has been employed in the study of biological macromolecules such as proteins ${ }^{35,36}$ and carbohydrates. ${ }^{37,38}$ A range of polysaccharides has been studied by this approach. The sulphated polysaccharide heparin has been studied by a number of groups. ${ }^{38-41}$ It was found that adsorption at the interface depended on binding with an ionophore, ${ }^{38}$ which can be the organic electrolyte cation. ${ }^{39}$ Guo et al. studied several hydrophobic quaternary ammonium cations as heparin selective ionophores and found that heparin adsorption was facilitated via complexation with such cations. ${ }^{40}$ Yudi and colleagues evaluated several cationic polysaccharides (chitosan, polyquaternium-4, diethylaminoethyl dextran, polyquaternium-10) at the ITIES and found relationships between the polymer structure and adsorption at the interface. ${ }^{42}$ They observed no transfer processes at the interface when the charged groups were directly connected to the monomers; however when attached via flexible linkers, charge transfer processes consistent with enhanced counterion interactions were observed. $^{42}$ This group also explored complex formation between cationic cellulosic polymers and anionic fluorinated surfactants at the ITIES, finding that the binding was dominated by electrostatic and hydrophobic interactions. ${ }^{43}$ Moreover, it was revealed that cationic polysaccharides adsorption at the interface included interaction with the organic phase electrolyte anion. ${ }^{44}$

The present work explores the electrochemistry of fucoidan at the ITIES and examines whether this is a viable approach for its quantitative detection. Fucoidan from two species of brown algae were investigated, Fucus vesiculosus (bladderwrack) and Undaria pinnatifida (wakame), using a liquid-organogel microinterface array (i.e. $\mu$ ITIES array) for voltammetric characterization and detection. The results reveal that adsorption and counter-ion interactions are important in the electrochemical behaviour. Using the discovered behaviour, a detection limit of $1.8 \mu \mathrm{g} \mathrm{mL} \mathrm{m}^{-1}$ was achieved for fucoidan from $U$. pinnatifida in $10 \mathrm{mM} \mathrm{NaOH}$ and $2.3 \mu \mathrm{g} \mathrm{mL}^{-1}$ for this fucoidan in $\mathrm{pH}$-adjusted synthetic urine.

\section{Experimental}

\subsection{Reagents}

All reagents were obtained from Sigma-Aldrich Australia Ltd and were used as received, unless stated otherwise. The organic phase was prepared by dissolving bis(triphenylphosphoranylidene) tetrakis(4-chlorophenyl) borate (BTPPATPBCl), tetradodecylammonium tetrakis(4-chlorophenyl) borate (TDDATPBCl) or tridodecylmethylammonium tetrakis(4-chlorophenyl) borate (TDMATPBCl) in 1,6-dichlorohexane (1,6-DCH). This electrolyte solution (10 $\mathrm{mM})$ was then gelled by the addition of $10 \% \mathrm{w} / \mathrm{v}$ low molecular weight poly (vinylchloride) (PVC). ${ }^{45}$ The organic electrolyte salt BTPPATPBCl was prepared by metathesis of bis(triphenylphosphoranylidene)ammonium chloride (BTPPACl) and potassium tetrakis(4-chlorophenyl)borate (KTPBCl). ${ }^{46}$ The organic electrolyte salt TDMATPBCl was also prepared by metathesis of equimolar tridodecylmethylamonnium chloride (TDMACl) and potassium tetrakis(4-chlorophenyl)borate (KTPBCl). Fucoidans extracted from two brown algae species, Undaria pinnatifida and Fucus vesiculosus, were provided by Marinova Pty Ltd, with purities of $96 \%$ and $98 \%$, respectively; both were pharmagrade, de-acetylated and polydisperse in molecular weight with peak average molecular weights of $134 \mathrm{kDa}$ and $62 \mathrm{kDa}$, respectively. These were stored at $4{ }^{\circ} \mathrm{C}$. Fucoidan stock solutions were prepared weekly in aqueous $10 \mathrm{mM} \mathrm{NaOH}$ and stored at $4{ }^{\circ} \mathrm{C}$. Likewise, tetrapentylammonium $\left(\mathrm{TPenA}^{+}\right)$chloride was prepared in $10 \mathrm{mM} \mathrm{NaOH}$. A synthetic urine mixture ${ }^{47}$ containing ammonium chloride $\left(1.00 \mathrm{~g} \mathrm{~L}^{-1}\right)$, calcium chloride dihydrate $\left(1.103 \mathrm{~g} \mathrm{~L}^{-1}\right)$, creatinine $\left(1.10 \mathrm{~g} \mathrm{~L}^{-1}\right)$, potassium chloride $\left(1.60 \mathrm{~g} \mathrm{~L}^{-1}\right)$, potassium dihydrogen phosphate $(1.40$ $\left.\mathrm{g} \mathrm{L}^{-1}\right)$, sodium chloride $\left(2.295 \mathrm{~g} \mathrm{~L}^{-1}\right)$, sodium sulfate $\left(2.25 \mathrm{~g} \mathrm{~L}^{-1}\right)$ and urea $\left(25 \mathrm{~g} \mathrm{~L}^{-1}\right)$ was prepared and modified to $\mathrm{pH} 12$ with $\mathrm{NaOH}$ solution as needed. All aqueous solutions were prepared with de-ionised water from a USF Purelab plus UV system (resistivity: $18.2 \mathrm{M} \Omega \mathrm{cm}$ ). 


\subsection{Apparatus}

Electrochemical experiments were performed with an AUTOLAB PGSTAT302N electrochemical station (Metrohm, The Netherlands) with its NOVA software interface. The $\mu$ ITIES array used was defined by a micropore array silicon membrane, ${ }^{48}$ which consisted of thirty micropores in a hexagonal arrangement, each pore having a diameter of $22.4 \mu \mathrm{m}$, a pore centre-to-pore centre distance of $200 \mu \mathrm{m}$ and membrane thickness of $100 \mu \mathrm{m}$. The geometric area of the microinterface array (i.e. total cross-sectional area of the micropores) was $1.18 \times$ $10^{-4} \mathrm{~cm}^{2}$. These microporous silicon membranes were sealed onto the lower orifice of a glass cylinder using silicone rubber (acetic acid curing Selley's glass silicone). The organogel was introduced into the silicon micropore arrays via the glass cylinder with the aid of a pre-warmed glass Pasteur pipette. The setup was then set aside for at least 1 hour before use. When ready, the organic reference solution (composition: saturated BTPPACl, TDDACl or TDMACl in $10 \mathrm{mM} \mathrm{LiCl}$ ) was placed into the glass cylinder so as to sit on top of the gelled organic phase. The organogel/silicon membrane assembly was then immersed into the aqueous phase $(10 \mathrm{mM} \mathrm{NaOH}$, fucoidan in $10 \mathrm{mM} \mathrm{NaOH}$, and/or $\mathrm{TPenA}^{+}$in $10 \mathrm{mM} \mathrm{NaOH}$ ) and voltammetric experiments were implemented. Scheme 1 summarises the electrochemical cells employed and Fig. $\mathrm{S} 1 \dagger$ summarises the experimental set-up.

\subsection{Electrochemical measurements}

A pair of $\mathrm{Ag} / \mathrm{AgCl}$ electrodes, one in each phase, were used for all measurements. Cyclic voltammetry (CV) and adsorptive stripping voltammetry (AdSV) were carried out at a scan rate of $5 \mathrm{mV} \mathrm{s}^{-1}$ unless noted otherwise. Other parameters such as fucoidan concentration, applied potential, and duration of the pre-concentration step were varied accordingly. The calculated limits of detection were based on three times the standard deviation of the blank $(n=3)$ divided by the slope of the bestfit linear calibration line. All potentials were transposed to the Galvani potential scale based on the experimental mid-point

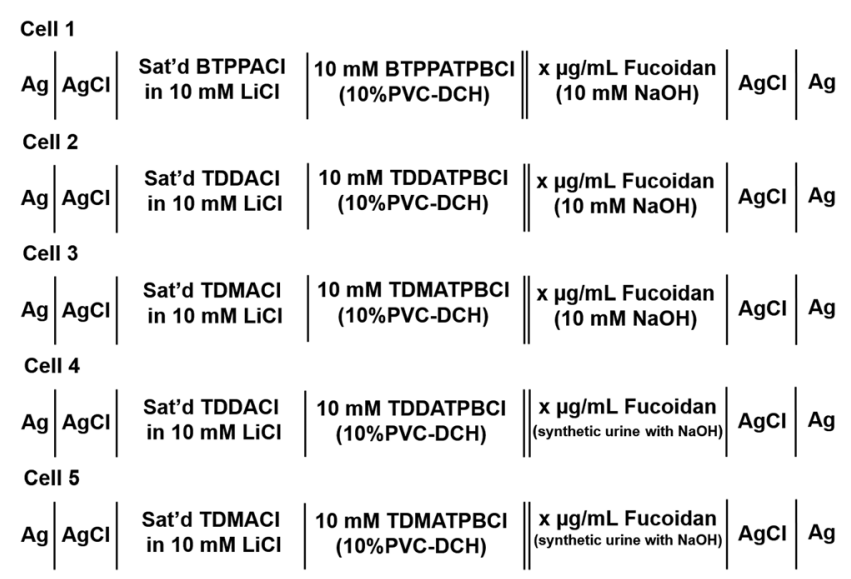

Scheme 1 Schematic representation of the electrochemical cells employed, where $x$ represents the fucoidan concentrations employed in the study. transfer potential of $\mathrm{TPenA}^{+}$and its formal transfer potential $(-0.35 \mathrm{~V})$ in the water|1,6-dichlorohexane system. ${ }^{49}$

\section{Results and discussion}

\subsection{Cyclic voltammetry}

Initial studies to probe the electrochemical behaviour at the $\mu$ ITIES array of the fucoidans extracted from Undaria pinnatifida and Fucus vesiculosus were conducted using cyclic voltammetry (CV). Various aqueous phase $\mathrm{pH}$ values were surveyed initially and it was found that the best response for analytical performance was observed at $\mathrm{pH} 12(10 \mathrm{mM} \mathrm{NaOH})$. Fig. 1 shows CVs of $U$. pinnatifida fucoidan studied using Cells 1-3 (Scheme 1). Fig. 1A (black line) illustrates the CV obtained when $1 \mathrm{mg} \mathrm{mL}^{-1} U$. pinnatifida fucoidan was present in the aqueous phase, while inset (top right) is that of $1 \mathrm{mg} \mathrm{mL}^{-1}$ F. vesiculosus fucoidan. Both figures also show the voltammograms obtained when only the background electrolytes (dashed grey line) were present. On scanning from positive toward more negative potentials, the transfer of background electrolytes across the ITIES was indicated by the decrease of negative current going towards more negative potentials. This process at the negative potentials corresponds to the transfer of the anions $\left(\mathrm{OH}^{-}\right)$from the aqueous phase to the organogel and the cations $\left(\mathrm{BTPPA}^{+}\right)$from the organic to the aqueous phase, whilst at the positive end of the voltammograms the increase in current is due to the opposite effect, i.e. $\mathrm{Na}^{+}(\mathrm{aq} \rightarrow$ org $)$ and $\mathrm{TPBCl}^{-}($org $\rightarrow$ aq) transfers. A sharp peak
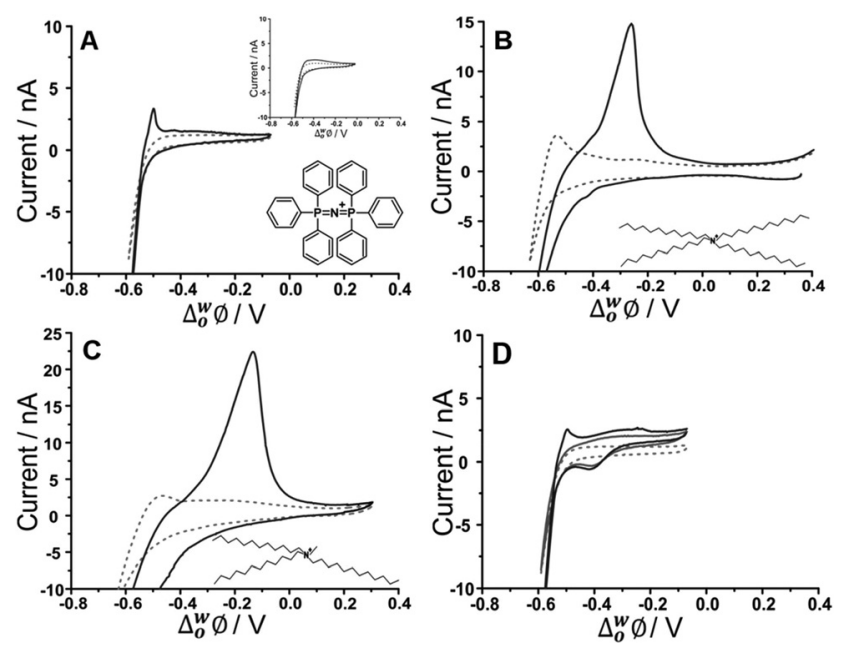

Fig. 1 Cyclic voltammograms of $10 \mathrm{mM} \mathrm{NaOH}$ (pH 12) in the absence (grey dashed line) and presence (black line) of $1 \mathrm{mg} \mathrm{mL}^{-1} U$. pinnatifida fucoidan using (A) Cell 1 and (top inset) F. vesiculosus; (B) Cell 2 and (C) Cell 3 all in Scheme 1. (D) CVs recorded in the absence (grey dashed

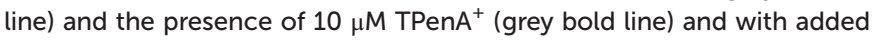
$1 \mathrm{mg} \mathrm{mL}^{-1} U$. pinnatifida fucoidan (black line) using Cell 1. Scan rate: $5 \mathrm{mV} \mathrm{s}^{-1}$. Scan direction: towards negative potential; species transferred at the negative potential limit: $\left(\mathrm{OH}^{-}\right.$aq $\rightarrow$ org), $\left(\mathrm{BTPPA}^{+} / \mathrm{TDDA}^{+} / \mathrm{TDMA}^{+}\right.$ org $\rightarrow$ aq). Bottom inset: Chemical structures of (A) BTPPA ${ }^{+}$; (B) TDDA ${ }^{+}$; (C) TDMA ${ }^{+}$. 
response was observed at $c a .-0.50 \mathrm{~V}$ on the reverse scan of the CV for $U$. pinnatifida fucoidan (Fig. 1A), while an insignificant broad wave was observed for $F$. vesiculosus fucoidan at $c a$. $-0.45 \mathrm{~V}$ (Fig. 1A inset top right). The different responses obtained may be attributed to the structural differences of the two fucoidan species. ${ }^{50} \mathrm{U}$. pinnatifida fucoidan contains more galactose and has a higher peak molecular weight distribution. This may introduce a conformational flexibility of $U$. pinnatifida fucoidan that enables a higher affinity for the organic cation of the organogel electrolyte phase. This also bears some resemblance to the behaviour of proteins at the ITIES, which can alter their conformation upon interaction with the organic phase. ${ }^{51-53}$

To further investigate counterion-polyion interaction, two alternative organic phase electrolyte cations, as described in Cells 2 and 3 (Scheme 1) were used in order to determine whether this influences the behaviour of the fucoidan polyelectrolyte at the polarised aqueous-organogel interface. Tetradodecylammonium (TDDA ${ }^{+}$and tridodecylmethylammonium $\left(\mathrm{TDMA}^{+}\right)$replaced the commonly used organic cation bis(triphenyl)phosphoranylidene (BTPPA ${ }^{+}$). Fig. 1B illustrates the $\mathrm{CV}$ obtained when $1 \mathrm{mg} \mathrm{mL}^{-1} U$. pinnatifida fucoidan was present in the aqueous phase and $10 \mathrm{mM}$ TDDATPBCl in the organic phase, while Fig. $1 \mathrm{C}$ shows the $\mathrm{CV}$ when $1 \mathrm{mg} \mathrm{mL} \mathrm{m}^{-1}$ $U$. pinnatifida fucoidan was present in the aqueous phase and $10 \mathrm{mM}$ TDMATPBCl was in the organic phase. With the use of these alkylammonium cations in the organic phase, the observed potential window was extended on the negative potential side. This can be attributed to the fact that $\mathrm{TDDA}^{+}$ transfers at a more negative potential ${ }^{54}$ than BTPPA $^{+}$and, since it is structurally similar, $\mathrm{TDMA}^{+}$was expected to do the same. However, the major difference observed was the intensity of the $U$. pinnatifida fucoidan response in the presence of $\mathrm{TDDA}^{+}$(Fig. 1B) and $\mathrm{TDMA}^{+}$(Fig. 1C) relative to $\mathrm{BTPPA}^{+}$ (Fig. 1A). In the presence of $U$. pinnatifida fucoidan (Fig. 1A-C), the distinct peaks observed on the reverse scans signify that $U$. pinnatifida fucoidan is electrochemically active at the $\mu$ ITIES array. A similar response was observed by Samec's group ${ }^{39}$ for another sulfated polysaccharide, heparin. The peaks exhibit a rapid decrease in current to the background levels, consistent with consumption of a finite amount of material at the interface. This behaviour is typical of an adsorption/desorption process. ${ }^{55}$ This reverse scan peak is therefore proposed to be the desorption of $U$. pinnatifida fucoidan from the interface which, in turn, suggests that it undergoes electroadsorption during the forward scan. On the other hand, Fig. 1D shows a voltammogram when $10 \mu \mathrm{M} \mathrm{TPenA}^{+}$(grey solid line) was present in the aqueous phase. It shows a steady-state voltammogram on the scan towards the positive potentials, indicative of radial diffusion, ${ }^{56}$ and a peak-shaped voltammogram on the scan towards negative potentials, representative of linear diffusion. This voltammogram indicates the mass transportcontrolled transfer of TPenA ${ }^{+}$at the $\mu$ ITIES array formed by the silicon micropore array membranes, in agreement with previous work ${ }^{57}$ as well as that the fucoidan is not adsorbed in the potential region where TPenA ${ }^{+}$transfers across the ITIES.
CVs of increasing $U$. pinnatifida fucoidan concentration (10-1000 $\mu \mathrm{g} \mathrm{mL}{ }^{-1}$ for BTPPA ${ }^{+}$and $\mathrm{TDDA}^{+} ; 5-25 \mu \mathrm{g} \mathrm{mL}{ }^{-1}$ for $\mathrm{TDMA}^{+}$) are shown in Fig. 2. Fig. 2A shows the experiment with an organic phase containing $10 \mathrm{mM} \mathrm{BTPPA}^{+}$. On the forward scan (towards negative potential), the previously-seen (Fig. 1A) increase in negative current is observed despite the
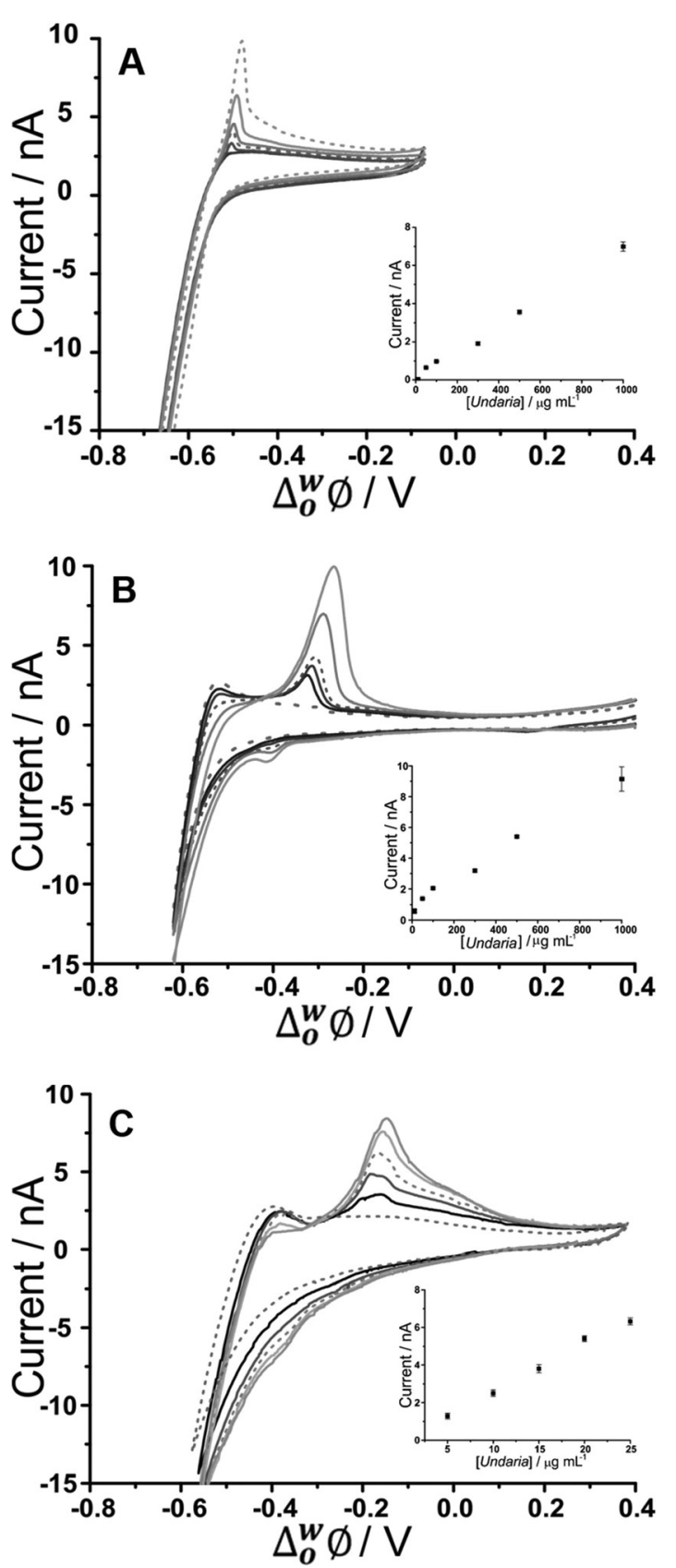

Fig. 2 Cyclic voltammograms of different U. pinnatifida fucoidan concentrations $\left(10-1000 \mu \mathrm{g} \mathrm{mL}^{-1}\right.$ for A\&B; $5-25 \mu \mathrm{g} \mathrm{mL} \mathrm{m}^{-1}$ for $\mathrm{C}$ in $10 \mathrm{mM}$ $\mathrm{NaOH}$ (pH 12). Cell 1, 2 and 3 respectively (Scheme 1). Scan rate: $5 \mathrm{mV} \mathrm{s}^{-1}$. Inset: Plot of peak current against $U$. pinnatifida fucoidan concentration. Scan direction: towards negative potential; species transferred at the negative potential limit: $\left(\mathrm{OH}^{-}\right.$aq $\rightarrow$ org), $\left(\mathrm{BTPPA}^{+} / \mathrm{TDDA}^{+} / \mathrm{TDMA}^{+}\right.$ org $\rightarrow$ aq). 
added $U$. pinnatifida fucoidan. Meanwhile, on the reverse scan, the peak height increased with increasing concentrations. Once again, the peak shapes are suggestive of a desorption process rather than a diffusion-controlled process. As a result, it is suggested that the response mechanism involves adsorption of $U$. pinnatifida fucoidan at the interface during the negative-going forward scan, possibly combined with the interaction of the polyanion with the cation of the organic phase electrolyte (BTPPA ${ }^{+}$), as discussed ${ }^{38}$ for heparin. The peak on the reverse scan (toward positive potential) is then attributed to a desorption process encompassing the dissociation of the complex formed between the polyanionic $U$. pinnatifida fucoidan and the organic electrolyte cation. Counterion-polyion interactions have been observed in several polyelectrolyte systems at the ITIES, ${ }^{43,44,58}$ and may reflect a generic mechanism for the electrochemical detection of polyionic analytes. CVs of increasing concentrations $\left(10-1000 \mu \mathrm{g} \mathrm{mL} \mathrm{mL}^{-1}\right)$ of $U$. pinnatifida fucoidan in contact with organic phases containing $10 \mathrm{mM} \mathrm{TDDA}^{+}$and $\left(5-25 \mu \mathrm{g} \mathrm{mL}{ }^{-1}\right) 10 \mathrm{mM} \mathrm{TDMA}^{+}$are shown in Fig. 2B and $\mathrm{C}$, respectively. A peak was observed at ca. $-0.30 \mathrm{~V}$ for $10 \mu \mathrm{g} \mathrm{mL^{-1 }} \mathrm{U}$. pinnatifida fucoidan with $\mathrm{TDDA}^{+}$ and at ca. $-0.15 \mathrm{~V}$ for $5 \mu \mathrm{g} \mathrm{mL}^{-1} U$. pinnatifida fucoidan with $\mathrm{TDMA}^{+}$, whereas in the presence of organic phase $\mathrm{BTPPA}^{+}, \mathrm{a}$ peak was observed only at the higher concentration of $50 \mu \mathrm{g} \mathrm{mL}$ (Fig. 2A). In the presence of the alkylammonium organic phase cations, the improvement in response might be attributed to a stronger interaction between $U$. pinnatifida fucoidan with $\mathrm{TDMA}^{+}$or $\mathrm{TDDA}^{+}$than with $\mathrm{BTPPA}^{+}$. Sulfated polysaccharides, like heparin, ${ }^{39}$ are known to form complexes with cations that serve as ionophores $;^{39,41}$ such studies have determined that weak heparin-cation interactions were observed when BTPPA $^{+}$was used in the organic phase but an improved interaction was seen when hexadecyltrimethylammonium was used. Structurally, it was suggested there was more flexibility for the heparin to interact with hexadecyltrimethylammonium than with BTPPA $^{+}$due to steric hindrance from the phenyl rings in the latter which surround and shield the cationic centre. $^{39}$ Another study, by Guo et al. ${ }^{40}$ found that heparin adsorption at the ITIES was favourable when there was less steric hindrance within the ionophore so that the positive charge of the quaternary ammonium nitrogen was more accessible for electrostatic binding with heparin's negative charges. A similar phenomenon may be responsible for the observed enhanced electrochemical signal for fucoidan when $\mathrm{TDDA}^{+}$is employed in the organic phase, and more so with $\mathrm{TDMA}^{+}$, since there are structural similarities amongst the three cations hexadecyltrimethylammonium, $\mathrm{TDDA}^{+}$and $\mathrm{TDMA}^{+}$. This was also the case when Meyerhoff and co-workers ${ }^{30}$ used $\mathrm{TDMA}^{+}$based polyion-sensitive potentiometric electrodes to detect pentosan polysulfate and they found out that the more available charge density in $\mathrm{TDMA}^{+}$improves the strength of the ion-pairing interaction with the target polyion. These results indicate that fucoidan interaction becomes more favourable in the order of $\mathrm{BTPPA}^{+}<\mathrm{TDDA}^{+}<\mathrm{TDMA}^{+}$as the organic electrolyte cation. The interaction at the ITIES is therefore suggested to be the complexation of $U$. pinnatifida fucoidan with $\mathrm{TDDA}^{+}$or $\mathrm{TDMA}^{+}$at the microinterface, followed by adsorption of the complex during the forward scan (in the negative direction); this adsorbed complex is subsequently desorbed during the reverse scan (in the positive direction).

\subsection{Adsorptive stripping voltammetry}

Adsorptive stripping voltammetry (AdSV) has been implemented at the microITIES as a detection tool for several polyelectrolytes. ${ }^{40,59,60}$ This technique entails the application of a constant potential to drive adsorption for a defined time, which serves to pre-concentrate the analyte at the interface; a subsequent voltammetric scan, the detection step, desorbs the analyte from the interface and produces a current peak as the analytical signal. In the case of fucoidan, preconcentration at a suitable negative potential, to promote adsorption, followed by scanning to more positive potentials, to desorb it from the interface, can produce a peak current that is dependent on concentration and adsorption time. For optimization of the fucoidan adsorption parameters, the effect of applied potential during the adsorption step was first examined. Chosen potential values were applied for a certain time and were followed with a voltammetric scan towards positive potentials in order to desorb the fucoidan and produce a stripping voltammogram. Fig. 3 displays the effect of changing the adsorption potential on the detection of $U$. pinnatifida fucoidan in conjunction with the three different organic phase cations. In the presence of organic phase $\mathrm{BTPPA}^{+}$, at less negative adsorption potentials, the stripping voltammograms display no clear peak, but at adsorption potentials $\leq-0.55 \mathrm{~V}$ (Fig. 3A), a welldefined stripping peak is present, illustrating the influence of potential on the adsorption process. In a similar way, defined stripping peaks were observed when the organic phase cation $\mathrm{BTPPA}^{+}$was replaced with $\mathrm{TDDA}^{+}$or $\mathrm{TDMA}^{+}$, although in these cases the peaks started to appear following adsorption at a more positive potential $\left(\leq-0.50 \mathrm{~V}\right.$ for $\mathrm{TDDA}^{+}$and $\leq-0.40 \mathrm{~V}$ for $\mathrm{TDMA}^{+}$, Fig. 3B and $\mathrm{C}$, respectively). This difference can be attributed to the degree of interaction between the fucoidan and the organic electrolyte cation, as already discussed in the CV studies section.

As seen in the CV experiments, the AdSV peaks exhibit the shape of a surface-confined process, consistent with adsorption/desorption at the interface. One important point to consider in optimising the applied potential for adsorption is that the background electrolyte signal, which occurs near the $U$. pinnatifida fucoidan adsorption region, can also be minimised. Thus, the adsorption potential is crucial to both maximising the analytical signal and minimising the background signal. From the data in Fig. 3A, the optimised adsorption potential was determined to be $-0.59 \mathrm{~V}$ for $U$. pinnatifida fucoidan in the presence of organic phase BTPPA ${ }^{+}$; the same value was found for $F$. vesiculosus fucoidan (data not shown). AdSV following preconcentration at more negative potentials resulted in a stripping peak with a shoulder, which is due to background electrolyte transfer free of fucoidan interactions (Fig. 3A inset). In the presence of organic phase $\mathrm{TDDA}^{+}$or $\mathrm{TDMA}^{+}$, the best adsorption potentials, a compromise between 

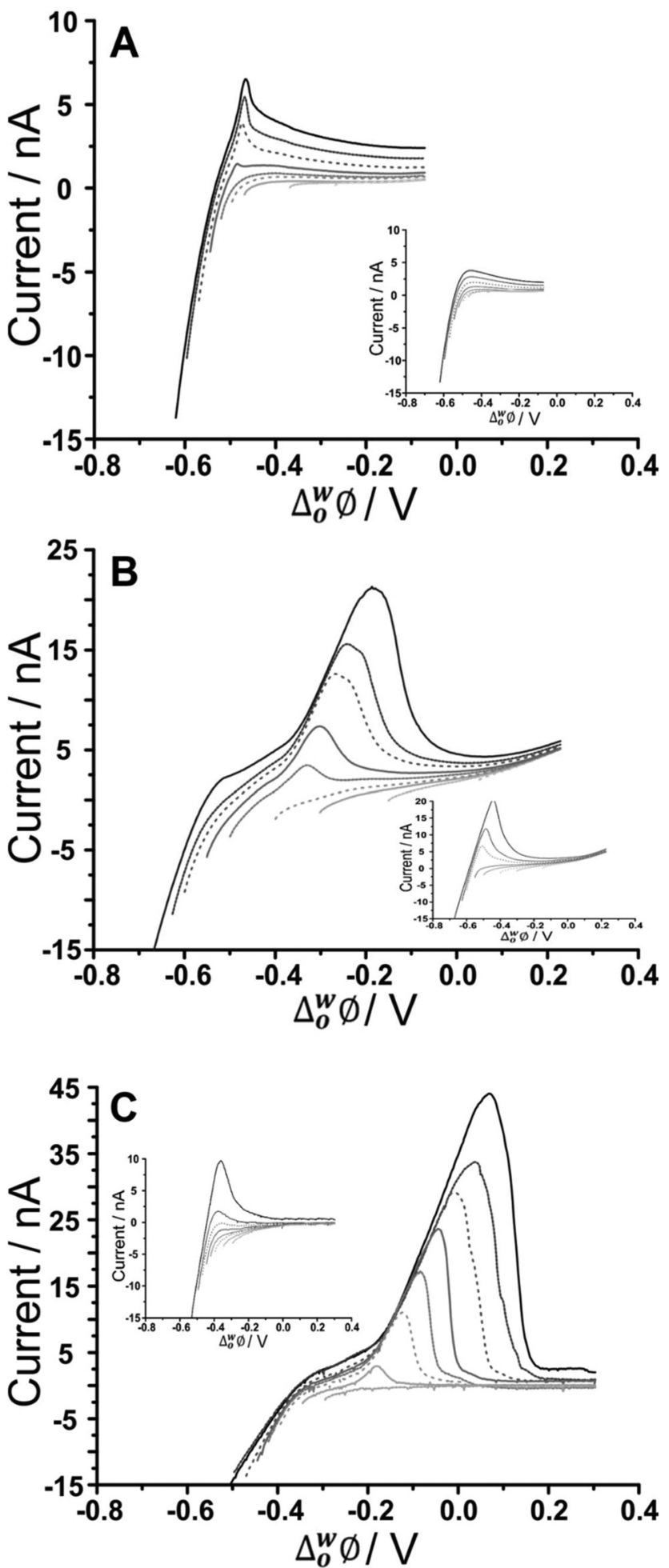

Fig. 3 AdSV in the presence and absence (inset) of $500 \mu \mathrm{g} \mathrm{mL}^{-1}$ $U$. pinnatifida fucoidan, in aqueous phase of $10 \mathrm{mM} \mathrm{NaOH}(\mathrm{pH}$ 12) following adsorption at different potentials. Adsorption time: $60 \mathrm{~s}$, (A) Cell 1, (B) Cell 2, and (C) Cell 3 (Scheme 1). Scan rate: $5 \mathrm{mV} \mathrm{s}^{-1}$.

the fucoidan desorption peak and the background electrolyte contribution, were found to be $-0.62 \mathrm{~V}$ for $U$. pinnatifida fucoidan (Fig. 3B) and F. vesiculosus fucoidan (Cell 2, Scheme 1) as well as $-0.47 \mathrm{~V}$ (Fig. 3C) for U. pinnatifida fucoidan (Cell 3, Scheme 1). These optimised adsorption potentials were utilised to determine the effect of varying adsorption time on the peak currents.

Moreover, the effect of varying the adsorption time was investigated for the different organic cations. No stripping peak was observed for $20 \mu \mathrm{g} \mathrm{mL}^{-1}$ U. pinnatifida fucoidan when $5 \mathrm{~s}$ adsorption time was employed with $\mathrm{BTPPA}^{+}$organic phase cation. However, AdSV with $60 \mathrm{~s}$ adsorption time at the same concentration produced a small peak which increased with the adsorption time. A similar trend was observed for F. vesiculosus fucoidan when $300 \mu \mathrm{g} \mathrm{mL}^{-1}$ was present in the aqueous phase. Note that a blank analysis was performed after each AdSV to check if any carryover of fucoidan was present; no peaks indicating such carryover were observed. In comparison to the previous experiment with $\mathrm{BTPPA}^{+}$as the organic electrolyte cation, longer pre-concentration times with $\mathrm{TDDA}^{+}$ revealed no significant current increase in the blank AdSVs. Accordingly, the chosen adsorption times were 5, 60 and $180 \mathrm{~s}$ for both $\mathrm{TDDA}^{+}$and $\mathrm{TDMA}^{+}$organic phase cations. A current peak at $c a . \quad-0.30 \mathrm{~V}$ was observed when $20 \mu \mathrm{g} \mathrm{mL^{-1 }}$ U. pinnatifida fucoidan was present in the aqueous phase following $60 \mathrm{~s}$ pre-concentration in combination with organic phase $\mathrm{TDDA}^{+}$. However, for a $5 \mathrm{~s}$ preconcentration time, a current peak at $c a$. $-0.20 \mathrm{~V}$ was observed for the same concentration of $U$. pinnatifida fucoidan with $\mathrm{TDMA}^{+}$in the organic phase. This peak current increased with the pre-concentration time. Based on these experiments, an adsorption time of $180 \mathrm{~s}$ was chosen for subsequent studies.

Furthermore, increasing fucoidan concentrations were investigated using the adsorption parameters. Fig. 4 shows the peak current versus $U$. pinnatifida fucoidan concentration plots with the different organic phase cations. The slope of the calibration plots becomes steeper in the order $\mathrm{BTPPA}^{+}<\mathrm{TDDA}^{+}<$ $\mathrm{TDMA}^{+}$, which indicates that sensitivity is improved with

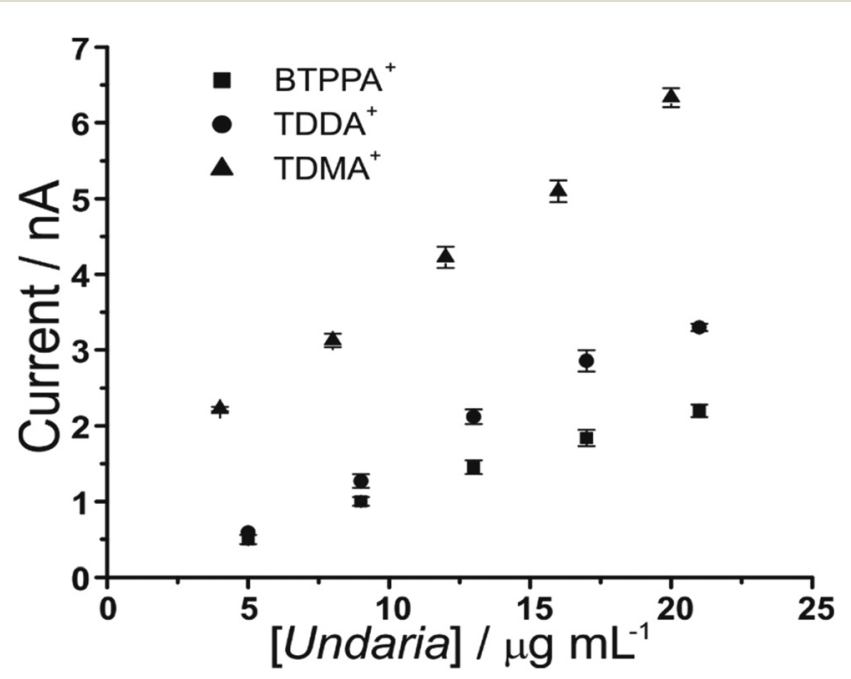

Fig. 4 Plot of peak current versus U. pinnatifida fucoidan concentrations using the optimised adsorption potential for each organic cation. Adsorption time: 180 s. Cells 1, 2 and 3 (Scheme 1). 
$\mathrm{TDMA}^{+}$as the organic cation. This is in agreement with the same observation from the CV studies in terms of the interaction between the fucoidan and the corresponding organic cations. The lowest detected $U$. pinnatifida fucoidan concen-

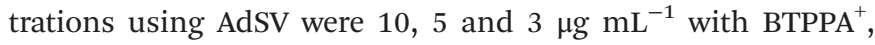
$\mathrm{TDDA}^{+}$, and $\mathrm{TDMA}^{+}$cations, respectively. Combined AdSV with organic phase $\mathrm{TDMA}^{+}$afforded a calculated detection limit of $1.8 \mu \mathrm{g} \mathrm{mL}{ }^{-1}$ for $U$. pinnatifida fucoidan.

\subsection{Matrix effects}

As fucoidan is commonly used as an ingredient in nutritional supplements, ${ }^{9}$ detection in physiological matrices, such as blood serum or urine, has been the subject of study. ${ }^{25}$ In the present study, synthetic urine was evaluated as a matrix for the detection of fucoidan. Synthetic urine was prepared as described elsewhere ${ }^{47}$ and was used as the aqueous phase of the electrochemical cell (see Cell 4 and 5, Scheme 1). It was found that some components of the synthetic urine decreased the potential window when they were added individually to the $10 \mathrm{mM} \mathrm{NaOH}$ aqueous phase; specifically, the cations $\left(\mathrm{NH}_{4}{ }^{+}\right.$, $\mathrm{K}^{+}, \mathrm{Ca}^{2+}$ ) were found to transfer at lower potentials. Fig. 5A shows a $\mathrm{CV}$ of the prepared $\mathrm{pH}$-adjusted $(\mathrm{pH} 12)$ synthetic urine (black solid line) overlayed on the $\mathrm{CV}$ recorded when $10 \mathrm{mM} \mathrm{NaOH}$ (grey dashed line) was the aqueous phase. This shows that the potential window was shorter when the synthetic urine was present, due to the easier transfer of some of its component ions. Despite the decreased potential window, it was found that, on spiking $U$. pinnatifida fucoidan into the synthetic urine aqueous phase ( $\mathrm{pH}$ adjusted with $\mathrm{NaOH}$ ), detection of $100 \mu \mathrm{g} \mathrm{mL^{-1 }} U$. pinnatifida fucoidan was possible using AdSV with $10 \mathrm{mM}^{\mathrm{TDDA}}{ }^{+}$in the organic phase. This is higher than achieved using a pure electrolyte aqueous phase so the other alternative organic phase cation, $\mathrm{TDMA}^{+}$was utilised based on the above observations of better interaction with $U$. pinnatifida Fucoidan (see Cell 5, Scheme 1).

Fig. 5B shows the CV obtained with synthetic urine as the aqueous phase (dashed grey line) and with added $1 \mathrm{mg} \mathrm{mL}$ $U$. pinnatifida fucoidan (black line). A peak at $c a$. $-0.20 \mathrm{~V}$ on the reverse scan (going positive) reveals the detection of the fucoidan in the biomimetic matrix. The sharp peak shape of the $\mathrm{CV}$ is indicative of an adsorption/desorption process, as discussed above. The intensity of the peak was more pronounced in comparison to the same fucoidan concentration studied using the $\mathrm{TDDA}^{+}$cation in this matrix. This is attributed to the structural flexibility of $\mathrm{TDMA}^{+}$that better exposes the positive charge of the nitrogen centre for electrostatic interaction with the negatively charged fucoidan. This was also observed by other groups for sulfated polyelectrolytes in biological matrices. ${ }^{30,40}$ AdSV with optimised parameters $(-0.35 \mathrm{~V}$ adsorption potential, $180 \mathrm{~s}$ preconcentration time) was used to improve the detection limit. Voltammograms of increasing (2-20 $\left.\mu \mathrm{g} \mathrm{mL}^{-1}\right) U$. pinnatifida fucoidan concentration are displayed in Fig. 5C. With the combined AdSV and enhanced interaction with $\mathrm{TDMA}^{+}$, a detection limit of $2.3 \mu \mathrm{g} \mathrm{mL} \mathrm{m}^{-1}$ for $U$. pinnatifida fucoidan in the $\mathrm{pH}$-adjusted synthetic urine
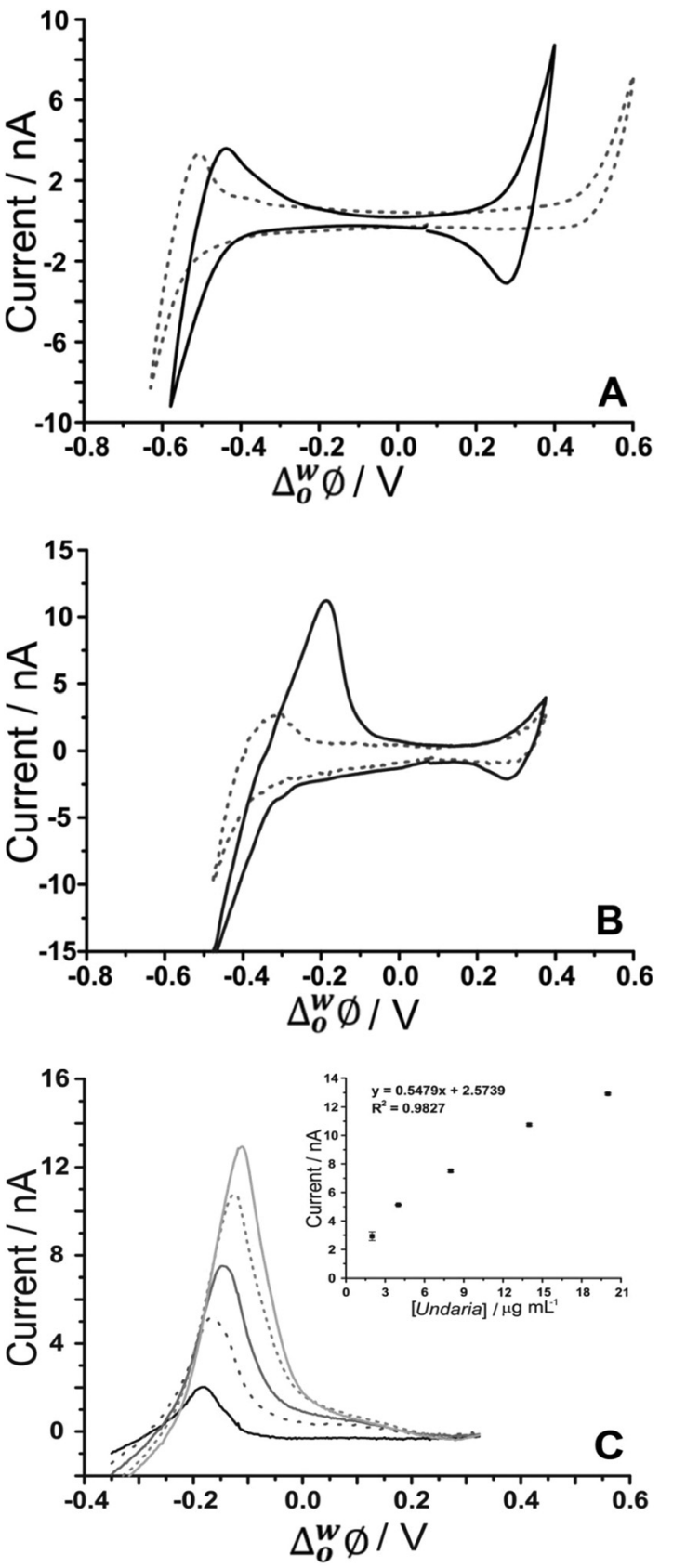

Fig. 5 (A) Cyclic voltammograms of $\mathrm{pH}$-adjusted synthetic urine (black line) in comparison to $10 \mathrm{mM} \mathrm{NaOH}$ ( $\mathrm{pH}$ 12) (grey dashed line) as the aqueous phase. (B) CV in the absence (grey dashed line) and presence of $1 \mathrm{mg} \mathrm{mL} \mathrm{m}^{-1} U$. pinnatifida (black line) (Cell 5, Scheme 1). (C) AdSV of increasing (background subtracted) $U$. pinnatifida fucoidan concentration $\left(2-20 \mu \mathrm{g} \mathrm{mL}^{-1}\right)$. Adsorption potential: $-0.35 \mathrm{~V}$, pre-concentration time: $180 \mathrm{~s}$, Cell 5 (Scheme 1), scan rate: $5 \mathrm{mV} \mathrm{s}^{-1}$.

matrix was achieved, which is comparable to the literature value of $2.5 \mu \mathrm{g} \mathrm{mL}^{-1}$ achieved with potentiometric titrimetry. ${ }^{31}$

It is important to note that the presence of additional surface-active species, like proteins, might be detrimental to applications in real biological matrix analyses. The presence of additional surface-active species might compete with the 
target analyte for adsorption to the interface. This could alter the stripping voltammogram, if the adsorption potential is near that of the fucoidan, and consequently, this could lower the sensitivity. However, careful optimisation of the electrolyte and adsorption potential conditions might help to alleviate this problem, as reported previously for insulin detection in the presence of serum albumin. ${ }^{61}$

\section{Conclusions}

The electrochemical behaviour of fucoidan was investigated using voltammetry at a $\mu$ ITIES array. The CV of $U$. pinnatifida fucoidan presented a distinct peak on the reverse scan at $c a$. $-0.50 \mathrm{~V}$ when the organic phase cation was BTPPA ${ }^{+}$. However, this potential shifted to $c a$. $-0.30 \mathrm{~V}$ when the organic phase cation was replaced with $\mathrm{TDDA}^{+}$and to $-0.175 \mathrm{~V}$ with $\mathrm{TDMA}^{+}$, as a result of the greater binding strength between these organic phase cations and $U$. pinnatifida fucoidan. The peak shape suggested it was a desorption process, consistent with adsorption during the forward scan to negative potentials. Investigation of the optimal adsorption potential for fucoidan at the interface revealed that maximum adsorption occurred at a potential just prior to the background electrolyte transfer. Using AdSV, the combination of $\mathrm{TDMA}^{+}$in the organic phase and pre-concentration for $180 \mathrm{~s}$ afforded a limit of detection of $1.8 \mu \mathrm{g} \mathrm{mL} \mathrm{m}^{-1}$ for $U$. pinnatifida fucoidan in $10 \mathrm{mM} \mathrm{NaOH}$ and $2.3 \mu \mathrm{g} \mathrm{mL} \mathrm{m}^{-1}$ in a $\mathrm{pH}$-adjusted synthetic urine solution. The behaviour identified here indicates the viability of using electrochemistry at the $\mu$ ITIES array as a label-free bioanalytical tool for the detection of fucoidan. Selectivity (i.e. differentiation between fucoidan species), targeting better cationic receptors in the organic phase and improving conditions with matrix effects are challenges that require further studies.

\section{Conflicts of interest}

Dr D.N. Stringer and Dr J.H. Fitton are employees of Marinova Pty Ltd.

\section{Acknowledgements}

BMBF thanks Curtin University for the award of a Curtin International Postgraduate Research Scholarship. The microporous silicon membranes were a gift from Tyndall National Institute, Cork, Ireland. Fucoidan materials studied in this work were a gift from Marinova Pty Ltd.

\section{References}

1 M. I. Bilan, A. A. Grachev, N. E. Ustuzhanina, A. S. Shashkov, N. E. Nifantiev and A. I. Usov, Carbohydr. Res., 2002, 337, 719-730.
2 L. Chevolot, B. Mulloy, J. Ratiskol, A. Foucault and S. Colliec-Jouault, Carbohydr. Res., 2001, 330, 529-535.

3 M. T. Ale and A. S. Meyer, RSC Adv., 2013, 3, 8131-8141.

4 O. Berteau and B. Mulloy, Glycobiology, 2003, 13, 29R-40R.

5 V. K. Morya, J. Kim and E.-K. Kim, Appl. Microbiol. Biotechnol., 2011, 93, 71-82.

6 W. Mak, N. Hamid, T. Liu, J. Lu and W. L. White, Carbohydr. Polym., 2013, 95, 606-614.

7 P. X. Sheng, Y.-P. Ting, J. P. Chen and L. Hong, J. Colloid Interface Sci., 2004, 275, 131-141.

8 M. E. Díaz-Rubio, J. Pérez-Jiménez and F. Saura-Calixto, Int. J. Food Sci. Nutr., 2009, 60, 23-34.

9 N. Ruocco, S. Costantini, S. Guariniello and M. Costantini, Molecules, 2016, 21, 551.

10 E. J. Kim, S. Y. Park, J.-Y. Lee and J. H. Y. Park, BMC Gastroenterol., 2010, 10, 1-11.

11 Y. H. Park, G.-Y. Kim, S.-K. Moon, J. W. Kim, H. Y. Yoo and H. Y. Choi, Molecules, 2014, 19, 5981-5998.

12 Y. Aisa, Y. Miyakawa, T. Nakazato, H. Shibata, K. Saito, Y. Ikeda and M. Kizaki, Am. J. Hematol., 2005, 78, 7-14.

13 J. H. Fitton, Mar. Drugs, 2011, 9, 1731-1760.

14 R. M. Lowenthal and J. H. Fitton, J. Appl. Phycol., 2014, 27, 2075-2077.

15 S. P. Myers, J. O’Connor, J. H. Fitton, L. Brooks, M. Rolfe, P. Connellan, H. Wohlmuth, P. A. Cheras and C. Morris, Biol.: Targets Ther., 2010, 4, 33-44.

16 S. P. Myers, J. O'Connor, J. H. Fitton, L. Brooks, M. Rolfe, P. Connellan, H. Wohlmuth, P. A. Cheras and C. Morris, Biol.: Targets Ther., 2011, 5, 45-60.

17 K. Hayashi, T. Nakano, M. Hashimoto, K. Kanekiyo and T. Hayashi, Int. Immunopharmacol., 2008, 8, 109-116.

18 R. Cooper, C. Dragar, K. Elliot, J. H. Fitton, J. Godwin and K. Thompson, BMC Complementary Altern. Med., 2002, 2, 17.

19 D. J. Schaeffer and V. S. Krylov, Ecotoxicol. Environ. Saf., 2000, 45, 208-227.

20 A. Pielesz and W. Biniaś, Carbohydr. Res., 2010, 345, 26762682.

21 A. Pielesz, W. Biniaś and J. Paluch, Carbohydr. Res., 2011, 346, 1937-1944.

22 Y. Yamazaki, Y. Nakamura and T. Nakamura, Plant Biotechnol., 2016, 33, 117-121.

23 U. Warttinger, C. Giese, J. Harenberg and R. Krämer, arXiv preprint arXiv:1608.00108, 2016.

24 M. R. Irhimeh, J. H. Fitton, R. M. Lowenthal and P. Kongtawelert, Methods Find. Exp. Clin. Pharmacol., 2005, 27, 705-710.

25 Y. Tokita, K. Nakajima, H. Mochida, M. Iha and T. Nagamine, Biosci., Biotechnol., Biochem., 2010, 74, 350357.

26 S. S. M. Hassan, M. E. Meyerhoff, I. H. A. Badr and H. S. M. Abd-Rabboh, Electroanalysis, 2002, 14, 439.

27 N. Dürüst and M. E. Meyerhoff, J. Electroanal. Chem., 2007, 602, 138-141.

28 B. Fu, E. Bakker, V. C. Yang and M. E. Meyerhoff, Macromolecules, 1995, 28, 5834-5840. 
29 J. Langmaier, Z. Samec, E. Samcová and P. Tůma, Electrochem. Commun., 2012, 24, 25-27.

30 N. Dürüst and M. E. Meyerhoff, Anal. Chim. Acta, 2001, 432, 253-260.

31 J. M. Kim, L. Nguyen, M. F. Barr, M. Morabito, D. Stringer, J. H. Fitton and K. A. Mowery, Anal. Chim. Acta, 2015, 877, 1-8.

32 G. Herzog, Analyst, 2015, 140, 3888-3896.

33 P. Peljo and H. H. Girault, Encyclopedia of Analytical Chemistry, 2012.

34 S. Liu, Q. Li and Y. Shao, Chem. Soc. Rev., 2011, 40, 22362253.

35 T. Osakai, Y. Yuguchi, E. Gohara and H. Katano, Langmuir, 2010, 26, 11530-11537.

36 B. M. B. Felisilda, E. Alvarez de Eulate and D. W. M. Arrigan, Anal. Chim. Acta, 2015, 893, 34-40.

37 H. A. Santos, V. García-Morales, R.-J. Roozeman, J. A. Manzanares and K. Kontturi, Langmuir, 2005, 21, 5475-5484.

38 S. Amemiya, Y. Kim, R. Ishimatsu and B. Kabagambe, Anal. Bioanal. Chem., 2011, 399, 571-579.

39 Z. Samec, A. Trojánek, J. Langmaier and E. Samcová, Electrochem. Commun., 2003, 5, 867-870.

40 J. Guo, Y. Yuan and S. Amemiya, Anal. Chem., 2005, 77, 5711-5719.

41 P. Jing, Y. Kim and S. Amemiya, Langmuir, 2009, 25, 1365313660.

42 J. S. Riva, C. I. Cámara, A. V. Juarez and L. M. Yudi, J. Appl. Electrochem., 2014, 44, 1381-1392.

43 J. S. Riva, K. Bierbrauer, D. M. Beltramo and L. M. Yudi, Electrochim. Acta, 2012, 85, 659-664.

44 J. S. Riva, R. Iglesias and L. M. Yudi, Electrochim. Acta, 2013, 107, 584-591.

45 M. D. Scanlon, J. Strutwolf and D. W. M. Arrigan, Phys. Chem. Chem. Phys., 2010, 12, 10040-10047.
46 T. Osakai, T. Kakutani and M. Senda, J. Electrochem. Soc., 1987, 134, C520-C520.

47 C. J. Collins, A. Berduque and D. W. M. Arrigan, Anal. Chem., 2008, 80, 8102-8108.

48 R. Zazpe, C. Hibert, J. O'Brien, Y. H. Lanyon and D. W. M. Arrigan, Lab Chip, 2007, 7, 1732-1737.

49 H. Katano and M. Senda, Anal. Sci., 2001, 17, 1027-1029.

50 T. T. M. Ho, K. E. Bremmell, M. Krasowska, D. N. Stringer, B. Thierry and D. A. Beattie, Soft Matter, 2015, 11, 21102124.

51 E. Alvarez de Eulate, L. Qiao, M. D. Scanlon, H. H. Girault and D. W. M. Arrigan, Chem. Commun., 2014, 50, 1182911832.

52 G. Herzog, W. Moujahid, J. Strutwolf and D. W. M. Arrigan, Analyst, 2009, 134, 1608-1613.

53 M. Arooj, N. S. Gandhi, C. A. Kreck, D. W. M. Arrigan and R. L. Mancera, J. Phys. Chem. B, 2016, 120, 3100-3112.

54 S. Wilke and T. Zerihun, J. Electroanal. Chem., 2001, 515, 52-60.

55 A. J. Bard and L. R. Faulkner, Electrochemical Methods: Fundamentals and Applications, John Wiley \& Sons, Inc., New York, 2001.

56 J. A. Campbell and H. H. Girault, J. Electroanal. Chem. Interfacial Electrochem., 1989, 266, 465-469.

57 J. Strutwolf, M. D. Scanlon and D. W. M. Arrigan, Analyst, 2009, 134, 148-158.

58 A. Trojánek, J. Langmaier, E. Samcová and Z. Samec, J. Electroanal. Chem., 2007, 603, 235-242.

59 S. Amemiya, X. Yang and T. L. Wazenegger, J. Am. Chem. Soc., 2003, 125, 11832-11833.

60 E. Alvarez de Eulate and D. W. M. Arrigan, Anal. Chem., 2012, 84, 2505-2511.

61 S. O'Sullivan, E. Alvarez de Eulate, Y. H. Yuen, E. Helmerhorst and D. W. M. Arrigan, Analyst, 2013, 138, 6192-6196. 